
and S. L. Mannan

\title{
Tensile Deformation and Work Hardening Behaviour of AISI 431 Martensitic Stainless Steel at Elevated Temperatures
}

https://doi.org/10.1515/htmp-2019-0028

Received Jul 03, 2018; accepted Jan 14, 2019

Abstract: Tensile deformation and fracture behaviour of AISI 431 martensitic stainless steel, over the temperature range of 300-823 $\mathrm{K}$, has been examined. Yield and ultimate tensile strength values decreased gradually from room temperature to intermediate temperatures, followed by a rapid decrease at high temperatures. At the intermediate temperatures (523-673 K), the steel exhibited jerky/serrated flow and anomalous variations in terms of a plateau in flow stress/strength and work hardening parameters and minima in ductility. These manifestations were identified to be the signatures of dynamic strain ageing, operating at these temperatures. At high temperatures, a rapid decrease in flow stress/strength values and increase in ductility with increasing temperature indicated the dominance of dynamic recovery. The fracture remained transgranular ductile at all temperatures. Work hardening relations that best described the flow behaviour of AISI 431 steel were identified. Variations of the work hardening parameters with temperature were consistent with the variations exhibited by strength and ductility values.

Keywords: AISI 431, Martensitic steel, Tensile properties, Dynamic Strain Ageing

\footnotetext{
^Corresponding Author: E. Isaac Samuel: Materials Development \& Technology Division, Indira Gandhi Centre for Atomic Research, Kalpakkam - 603102, Tamil Nadu, India; Email: isaac@igcar.gov.in; Tel.: +91 4427480500 (extn. 21172); Fax: +91 4427480075 Neeta Paulose, S. N. Narendra Babu, S. L. Mannan: Gas Turbine Research Establishment, Bengaluru - 560093, Karnataka, India M. Nandagopal, S. Panneer Selvi: Materials Development \& Technology Division, Indira Gandhi Centre for Atomic Research, Kalpakkam - 603102, Tamil Nadu, India
}

\section{Introduction}

AISI 431 steel is a 16Cr-2Ni martensitic stainless steel which exhibits excellent strength, toughness, and resistance to stress corrosion and oxidation up to $863 \mathrm{~K}[1,2]$. Hence these steels find application in chemical and power industries, and as compressor blades in marine and modern aircraft engines. These grades of martensitic stainless steel are used in quenched and tempered condition. Typically the martensitic stainless steels are hardened by heating to the austenitising temperature range of $1198-1338 \mathrm{~K}$, followed by air cooling or oil quenching. In austenitised condition, the steel exhibits high strength and hardness values, but with low ductility and toughness values. In order to obtain useful engineering properties, it is usual practice to employ a tempering treatment to these steel. On quenching $16 \mathrm{Cr}-2 \mathrm{Ni}$ steel from the austenitising temperature results in the formation of complex microstructure consisting of inherited $\delta$-ferrite, martensite and retained austenite with few undissolved $\mathrm{M}_{23} \mathrm{C}_{6}$ carbides [3, 4]. The chemical composition in terms of the balance between $\mathrm{Cr}$ - and $\mathrm{Ni}$ equivalents critically influence the resulting volume fraction of the above phases. Lower tempering temperatures of $573 \mathrm{~K}$ resulted in the transformation of retained austenite at lath boundaries to $\mathrm{Fe}_{3} \mathrm{C}$, whereas at higher tempering temperatures of above $673 \mathrm{~K}, \mathrm{Fe}_{3} \mathrm{C}$ progressively dissolves and $\mathrm{M}_{7} \mathrm{C}_{3}$ type carbides were observed to be precipitating. At tempering temperatures above $773 \mathrm{~K}, \mathrm{M}_{7} \mathrm{C}_{3}$ type carbides were replaced by $\mathrm{M}_{23} \mathrm{C}_{6}$. From the tempering studies on 16Cr-2Ni steel, Balan et al. [3] reported that the hardness values decreased on increasing tempering at $573 \mathrm{~K}$ from the as quenched values and exhibited a secondary hardening for the tempering temperatures of 673-773 K. Based on the transmission electron microscopy (TEM) observations and selected area diffraction pattern (SADP) analysis, the secondary hardening observed at $673 \mathrm{~K}$ was attributed to precipitation of fine austenite particles [3]. In 17Cr-2Ni steel, Liu Ning et al. [4] observed that ultra-high austenitising temperature resulted in presence of many $\delta$-ferrite net-

ð Open Access. (C) 2019 E. Isaac Samuel et al., published by De Gruyter. (Cc) BY tion 4.0 License 
Table 1: Chemical composition of AISI 431 martensitic stainless steel.

\begin{tabular}{cccccccccccccccc}
\hline Element & $\mathbf{C r}$ & $\mathbf{N i}$ & $\mathrm{Cu}$ & $\mathbf{M o}$ & $\mathbf{N b}$ & $\mathrm{Co}$ & $\mathbf{S n}$ & $\mathrm{Ti}$ & $\mathbf{V}$ & $\mathbf{C}$ & $\mathbf{S i}$ & $\mathbf{M n}$ & $\mathbf{P}$ & $\mathbf{S}$ & $\mathbf{F e}$ \\
\hline $\mathbf{W t} \%$ & 16.0 & 2.0 & 0.30 & 0.30 & 0.05 & 0.05 & 0.02 & 0.05 & 0.2 & 0.16 & 1.0 & 1.0 & 0.015 & 0.01 & Balance \\
\hline
\end{tabular}

works and few twinned martensite and hence did not improve the impact toughness of the steel. Tempering at 823 $\mathrm{K}$ resulted in lower impact energies due to temper embrittlement caused by segregation of phosphorus, chromium and nickel to prior austenite grain boundaries [4]. In Type 431 welds, it was reported that presence of nickel lowers $\mathrm{A}_{c 1}$ and hence in order to avoid re-austenitisation during tempering, it was suggested to have employed double tempering treatment at temperatures below $\mathrm{A}_{c 1}$ [5].

While considering material for component or structural applications, the tensile, creep and fatigue properties are of critical importance. Evaluation of high temperature tensile properties is a prerequisite mechanical characterization towards the performance of material at elevated temperatures. Room temperature tensile strength for AISI 431 steel is specified to vary between 800 and $1300 \mathrm{MPa}$ depending upon the tempering temperature, with ductility values greater than $20 \%$ [6]. In the present study, the influence of temperature on the tensile deformation and work hardening behaviour of AISI 431 martensitic stainless steel has been examined in the quenched and double tempered condition. The role of dynamic strain ageing manifested at the intermediate temperatures, and the dominance of dynamic recovery at high temperatures affecting tensile properties are discussed.

\section{Experimental}

AISI 431 steel plates of chemical composition conforming to that specified in ASTM standards [2] were obtained in quenched and double tempered condition. Chemical composition of the steel in weight percentages of the elements is given in Table 1. The material was subjected to quench hardening and double tempering treatment. Austenitising was carried out at $1283 \pm 10 \mathrm{~K}$ for 30 minutes, followed by quenching in oil. The hardened alloy was given a tempering treatment at $923 \pm 10 \mathrm{~K}$ followed by quenching in oil and again re-tempered at the same temperature and quenched in oil. Specimen blanks of $12 \mathrm{~mm}$ diameter and $60 \mathrm{~mm}$ length were cut along the rolling direction of the plate. Button head cylindrical specimens of $26 \mathrm{~mm}$ gauge length and $4 \mathrm{~mm}$ gauge diameter were machined from the specimen blanks. Tensile tests were carried out in air using a floor model Instron 1195 universal testing machine (UTM). The UTM was equipped with a three-zone temperature control furnace for precision temperature control and a steppedload suppression unit for fine load measurement. Tests were performed in the temperature range of $300-823 \mathrm{~K} \mathrm{em}$ ploying a nominal strain rate of $3 \times 10^{-3} \mathrm{~s}^{-1}$. Few additional tensile tests were also performed at the nominal strain rates of $3 \times 10^{-4}, 3 \times 10^{-5}$ and $3 \times 10^{-6} \mathrm{~s}^{-1}$ at selected temperatures to evaluate the occurrence of dynamic strain ageing. Load-elongation curves for all the test conditions were recorded using a data acquisition system attached to the tensile test system. Since no strain gauge was employed, the crosshead displacement was taken as the specimen extension and slope of the initial linear elastic portion of the load-elongation data is contributed by the specimen, machine frame, and load-train assembly. True stress $(\sigma)$ true plastic strain $(\epsilon)$ data were evaluated from the loadelongation data using a computer program up to the maximum load values corresponding to the onset of necking. The temperature during the tests was controlled within \pm 2 K. A strain resolution of $7.5 \times 10^{-4}$ and a stress resolution of $0.80 \mathrm{MPa}$ were obtained on the $\sigma-\epsilon$ data.

\section{Constitutive Description Tensile Flow Curve}

Plastic flow behaviour in terms of true stress $(\sigma)$ - true plastic strain $(\epsilon)$ plot for several metals and alloys in the uniform elongation regime had been well described using several empirical relations proposed in the literature. Hollomon relation [7] is the most widely used and is given as,

$$
\sigma=K_{1} \epsilon^{n_{1}},
$$

Where $K_{1}$ is the strength coefficient and $n_{1}$ is the strain hardening exponent. However, for materials exhibiting varied yield strength and yet having similar strain hardening behavior or in the case of materials exhibiting similar yield strength with different work hardening behavior, the yield and strain hardening cannot be described by a single relation, as in the case of Hollomon relationship [8]. Hence, introducing an additional term to the above power law relation in order to accommodate the mechanical history was considered. The positive deviation observed at 
the low strains due to yielding was accounted with an additional stress term $\left(\sigma_{0}\right)$, as in the case of Ludwik relation [9],

$$
\sigma=\sigma_{0}+K_{L} \epsilon^{n_{L}},
$$

or with an additional strain term $\left(\epsilon_{0}\right)$ to account the prestrain left in the material, as in the case of Swift relation [10],

$$
\sigma=K_{S}\left(\epsilon_{0}+\epsilon\right)^{n_{S}}
$$

where, $K_{L}$ and $K_{S}$ are the strength coefficient for Ludwik and Swift equations, respectively. $n_{L}$ and $n_{S}$ are the strain hardening exponents for Ludwik and Swift equations, respectively. Ludwigson [11] measured the positive stress deviations at low strains from the Hollomon relation and observed that the deviation stress values decreased exponentially with increasing strains and hence proposed the following relation,

$$
\sigma=K_{1} \epsilon^{n_{1}}+\exp \left(K_{2}+n_{2} \epsilon\right),
$$

where $K_{1}$ and $n_{1}$ are the same as in Hollomon equation and, $K_{2}$ and $n_{2}$ are additional constants.

For the materials exhibiting saturation in stress values at strains close to the onset of instability, Voce [12] proposed a flow relation as,

$$
\sigma=\sigma_{S}-\left(\sigma_{S}-\sigma_{I}\right) \exp \left(n_{V} \epsilon\right),
$$

where $\sigma_{I}$ and $\sigma_{S}$ are the initial and saturation stresses, respectively, and $n_{V}$ is a constant.

The above described constitutive relations were applied to the experimental true stress-true plastic strain data of AISI 431 steel using Levenberg-Marquardt least square method, with the unknown constants of the relation as free parameters. The goodness of the fit was indicated by the low $\chi^{2}$ value, the sum of the square of deviation of the calculated stress values from the experimental stress values. The lowest $\chi^{2}$ value indicated the high degree of goodness of fit.

\section{Results \& Discussions}

\subsection{Tensile Properties}

Figure 1 shows the typical tensile curve in terms of variations in engineering stress with engineering strain in the temperature range of $300-823 \mathrm{~K}$ at the nominal strain rate of $3 \times 10^{-3} \mathrm{~s}^{-1}$. Typically, the influence of temperature on the engineering tensile curve is observed as a systematic decrease in stress values with increasing temperature

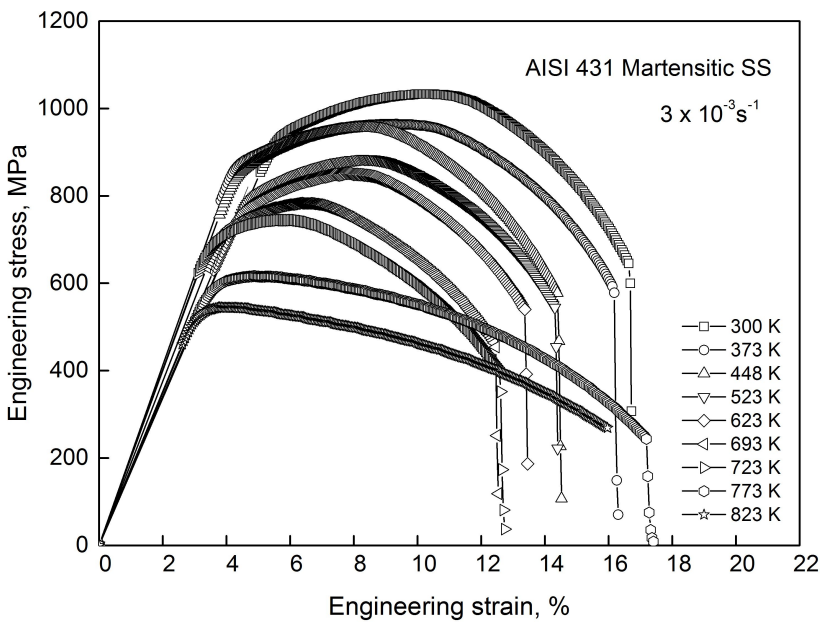

Figure 1: Variation of engineering stress as a function of engineering strain for the AISI 431 steel in the temperature range of 300-823 K.

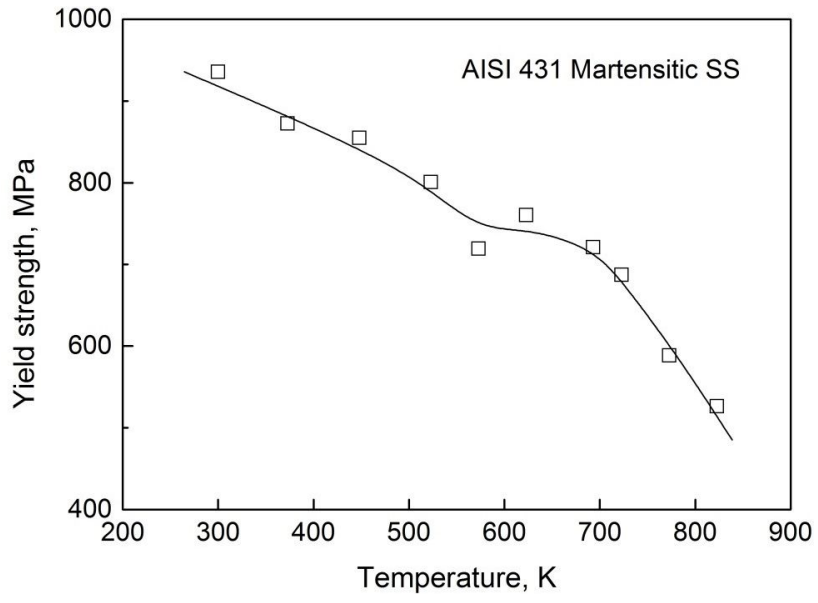

Figure 2: Variation of yield strength with temperature for the AISI 431 steel.

which is pronounced more significantly at engineering strains above the elastic limit. In Figure 1, the elongation to fracture was found to decrease with increasing temperatures up to $723 \mathrm{~K}$ and exhibited an increasing trend thereafter. However, the engineering strain to the onset of plastic instability, marked by the peak in engineering stress (Figure 1) was found to decrease systematically with increasing temperature. Figures 2 and 3 show the variation of yield strength and ultimate tensile strength, respectively, with increasing temperatures for the AISI 431 steel. The yield and ultimate tensile strength values decreased from room temperature values up to $523 \mathrm{~K}$ with increasing temperature. At the intermediate temperatures of 523 to 673 $\mathrm{K}$, the strength values exhibited a plateau, followed by a rapid decrease in strength values at temperatures above $673 \mathrm{~K}$. As shown in Figure 4, variation in uniform elongation values with temperature also exhibited a trend simi- 


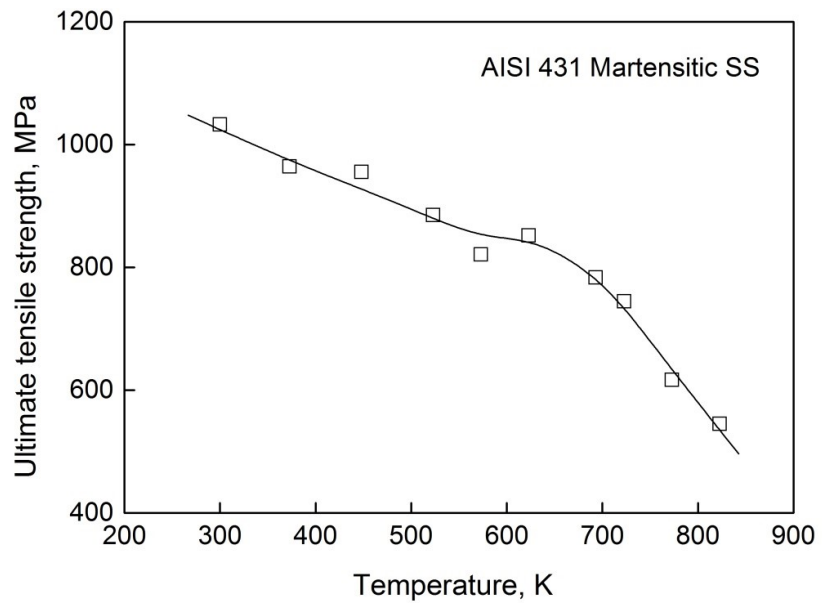

Figure 3: Variation of ultimate tensile strength with temperature for the AISI 431 steel.

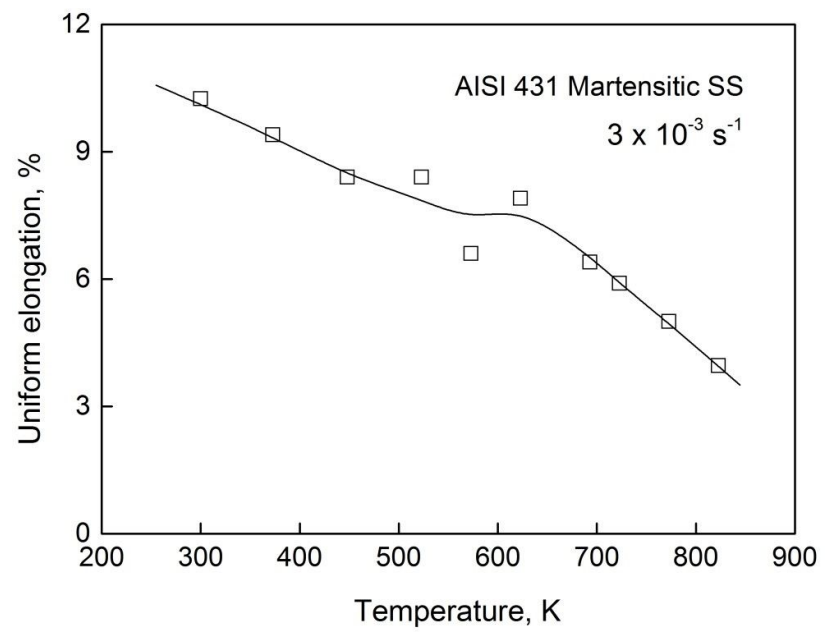

Figure 4: Variation of uniform elongation with temperature for the AISI 431 steel.

lar to that observed in strength values. Uniform elongation values decreased from 300 to $523 \mathrm{~K}$, followed by a plateau at intermediate temperatures (523-673 K) and a rapid decrease at high temperatures. However, the ductility values varied between 12.1 and $17.4 \%$, with minima occurring in the temperature region of 523-673 K, as shown in Figure 5. Figure 6 shows the variations in reduction in area with temperature. It may be observed that the values of reduction in area displayed a decreasing trend with increasing temperatures reaching a minimum at the intermediate temperatures and exhibited a rapidly increasing trend at high temperatures.

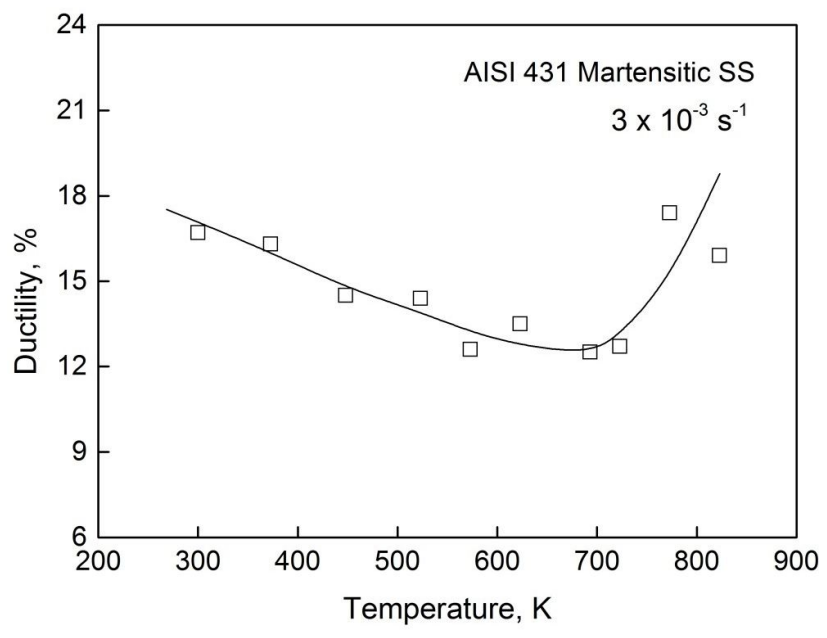

Figure 5: Variation of tensile ductility with temperature for the AISI 431 steel.

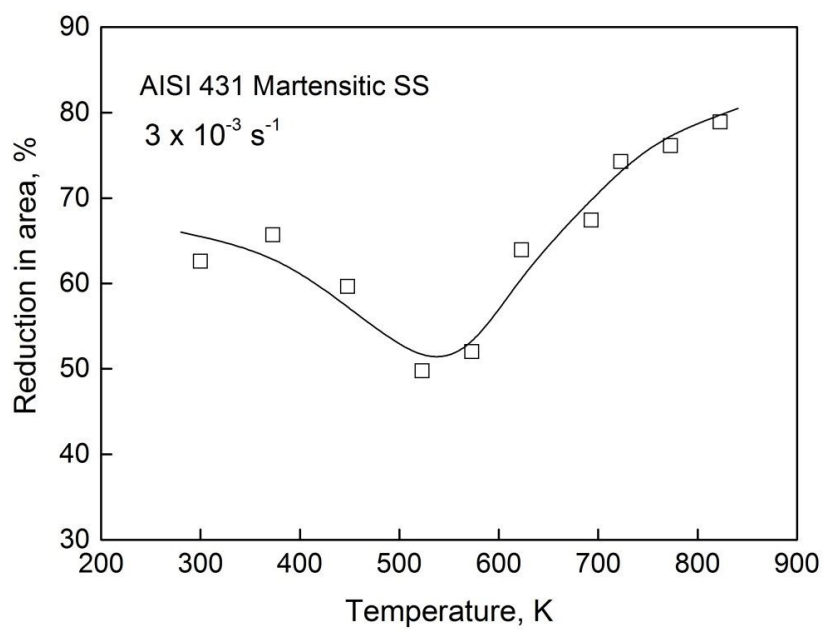

Figure 6: Variation of reduction in area with temperature for the AISI 431 steel.

\subsection{Tensile Fracture Behaviour}

At all temperatures examined, the fracture mode was observed to be transgranular ductile. As shown in Figure 7a, the low magnification images of the fractured surfaces exhibited star-like appearance for the specimen tested at room temperature (300 K). Figures $7 \mathrm{~b}$ and $7 \mathrm{c}$ show the fracture surface for specimen tested at intermediate (623 $\mathrm{K})$ and high temperature ( $823 \mathrm{~K})$, respectively, which reveal typical cup and cone fracture. With increasing temperature pronounced necking was observed (Figures 7a, $7 \mathrm{~b}$ and $7 \mathrm{c}$ ). It was also observed that coalescence of microvoids leads to the formation of dimples which governed the mode of fracture at all temperatures. At $300 \mathrm{~K}$ along with ductile dimples, large amount of splitting of martensitic lath boundaries which result in chisel tip ap- 

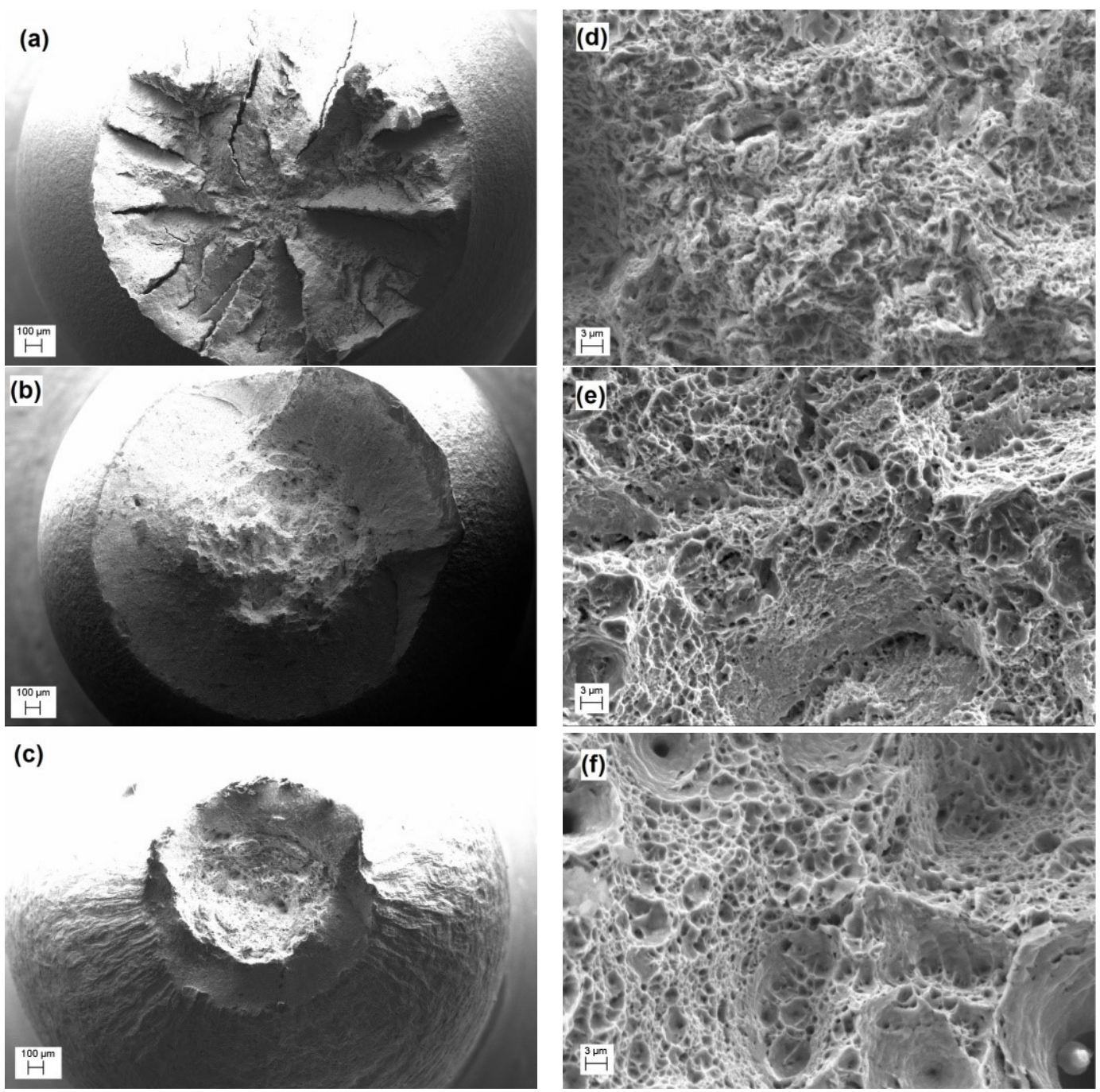

Figure 7: SEM images of fractured surfaces of AISI 431 steel specimen which were tensile tested at ( $a$ and $d) 300,(b$ and $e) 623$ and $(c$ and $f$ ) $823 \mathrm{~K}$.

pearance are seen in Figure 7d. However, with increasing temperature, chisel tip appearances reduce significantly and the fracture was dominated mainly by the presence of equiaxed dimples (Figure 7e). Increase in size of equiaxed dimples with increasing temperature indicates the decreasing number of microvoid nucleation and dominance of growth process at high temperatures as shown for $823 \mathrm{~K}$ in Figure $7 \mathrm{f}$.

The transgranular mode of fracture observed in the tensile deformation of AISI 431 steel for wide range of temperatures compares well with those reported for P9 and P91 ferritic-martensitic steels [13, 14]. Presence of secondary precipitates in the steel may also influence the chisel tip appearances caused by split in the martensitic lath boundaries. In thermally aged P9 steel, it had been shown that because of increased formation and growth of brittle Laves phase $\left(\mathrm{Fe}_{2} \mathrm{Mo}\right)$ at longer ageing durations, a large number of chisel tip appearance were observed [13]. Intergranular cracking cannot be the possible reason for the reduced strength values exhibited at elevated temperatures because of the observed transgranular fracture in the AISI 431 steel. Hence the observed rapid decrease in strength values at elevated temperatures is rationalised due to the effect of dynamic recovery. Also, the observed decrease in flow stress/strength values and increase in the ductility values at high temperatures can be attributed to the dominance of dynamic recovery at these temperatures (Figures 2-6).

\subsection{Influence of Dynamic Strain Ageing}

Anomalous variations were observed at the intermediate temperatures of 523-673 $\mathrm{K}$, in terms of a plateau in yield 
Table 2: Temperatures and strain rates at which serrations were observed at for AISI 431 martensitic stainless steel.

\begin{tabular}{|c|c|c|c|c|c|c|}
\hline & $423 \mathrm{~K}$ & $473 \mathrm{~K}$ & $523 \mathrm{~K}$ & $573 \mathrm{~K}$ & $623 \mathrm{~K}$ & $673 \mathrm{~K}$ \\
\hline $3 \times 10^{-3} \mathrm{~s}^{-1}$ & - & $X$ & $X$ & $x$ & 0 & $x$ \\
\hline $3 \times 10^{-4} \mathrm{~s}^{-1}$ & $x$ & $x$ & $x$ & 0 & $x$ & - \\
\hline $\mathbf{3} \times 10^{-5} \mathrm{~s}^{-1}$ & $x$ & $x$ & 0 & $x$ & $x$ & $x$ \\
\hline $\mathbf{3} \times 10^{-6} \mathrm{~s}^{-1}$ & - & - & 0 & - & $x$ & - \\
\hline
\end{tabular}

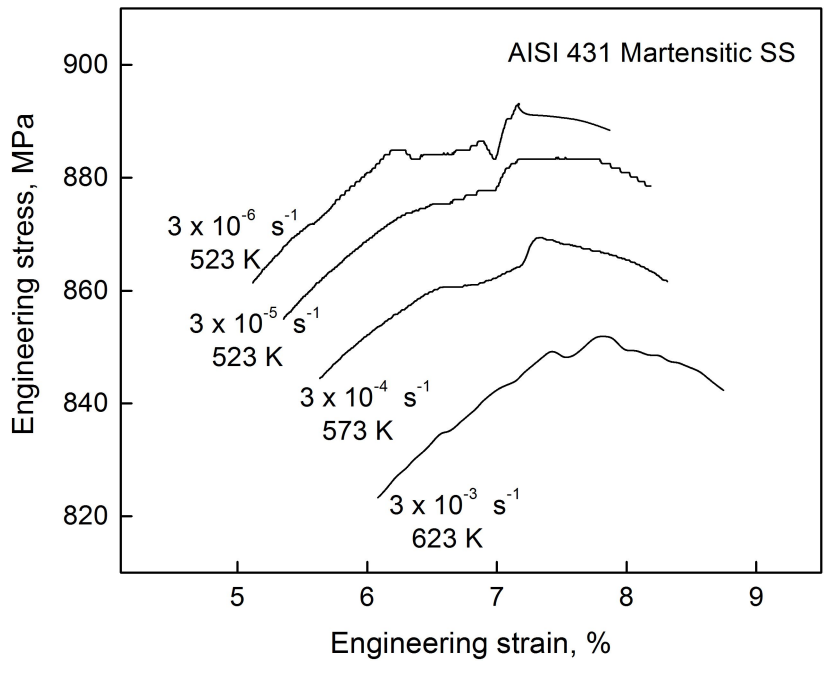

Figure 8: Typical serrations/jerky flow observed in the tensile engineering stress - engineering strain plot of AISI 431 martensitic stainless steel at 523-623 K.

strength, ultimate tensile strength, and uniform elongation values, and minima in ductility values. These anomalous variations could be attributed to the influence of Dynamic Strain Ageing (DSA) operating at these temperatures and strain rate. DSA, also known as Portevin LeChatelier effect, is caused by the dynamic interaction between solute atoms diffusing under the thermal activation and the mobile dislocations, driven by the imposed strain rate, during plastic deformation $[15,16]$. This phenomenon had been reported in 2.25Cr-1Mo [17], 9Cr-1Mo [18, 19], modified 9Cr-1Mo steels [20] and 316 SS [21]. In order to confirm the occurrence of DSA in the AISI 431 steel, few additional tests in the temperature range of $523-673 \mathrm{~K}$ were carried out employing strain rates ranging from $3 \times 10^{-6}$ to $3 \times 10^{-3} \mathrm{~s}^{-1}$.

AISI 431 steel exhibited serrated/jerky flow in the engineering tensile stress-strain curve, which is one of the manifestations of DSA. Serrations due to DSA had been classified into various types, identified as type A, B, C, D and E $[15,16]$. Type A serrations are locking serrations, characterized by an abrupt rise in stress value above the mean values, followed by a drop to below the general level of the stress-strain curve. Type B serrations are oscillations about the general level of the stress-strain curve that occur in quick succession due to discontinuous band propagation arising due to DSA. Type $\mathrm{C}$ serrations are considered to be due to the unlocking of dislocations leading to stress drops below the general level of the stress-strain curve. Type D serrations are plateaus in the flow curve due to band propagation, with no work hardening. Type A serrations change over to type $\mathrm{E}$ serrations at high strains as irregularities, with no work hardening during band propagation.

Figure 8 depicts the typical serrations / jerky flow observed at different temperatures and strain rates in the AISI 431 steel. As evident from the figure (Figure 8), the observed serrations could be identified to be Type D or mild irregularities. The occurrence of type D serrations results from negligible or small work hardening following a rapid initial increase in stress (Figure 8). The observed serrations were mild or irregular and the number of load drops or, the number of events of serrations in AISI 431 steel was observed to be significantly low compared to those obtained for P9, P91 and 316 steels [18-21]. These indicate reduced activity of serrated flow. Table 2 lists the temperature and strain rates under which the appearance of serrated/jerky flow was noticed in the tensile stress-strain curve. As shown in Figure 9, the steel exhibited negative strain rate sensitivity in terms of decreasing ultimate tensile strength values with increasing strain rate, which is one of the important manifestations of DSA. It may be noticed that though serrations were not observed for the applied nominal strain rates of $3 \times 10^{-4}$ and $3 \times 10^{-3} \mathrm{~s}^{-1}$ at $523 \mathrm{~K}$, the influence of DSA is reflected in the decrease in ultimate tensile strength values with increasing strain rate. The average macroscopic strain rate sensitivity was estimated to be $-6.97 \times 10^{-3}$ at ultimate tensile strength for $523 \mathrm{~K}$.

A plot of appearances of serrations/jerky flow in a ' $\log (\dot{\epsilon})$ vs 1000/T' space is shown in Figure 10. The slope of the boundaries separating the serrated flow regime from 


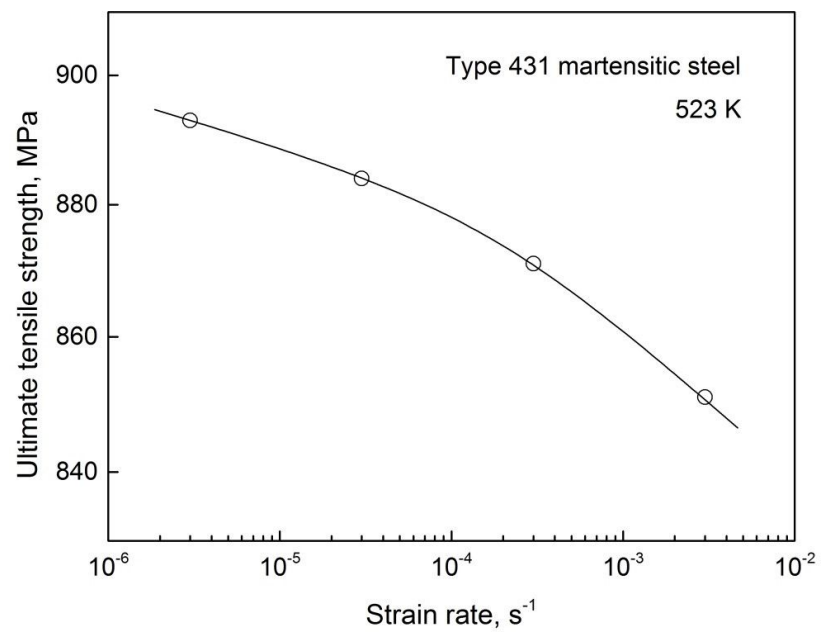

Figure 9: AISI 431 martensitic stainless steel exhibited negative strain rate sensitivity in terms of decreasing ultimate tensile strength values with increasing nominal strain rate at $523 \mathrm{~K}$.

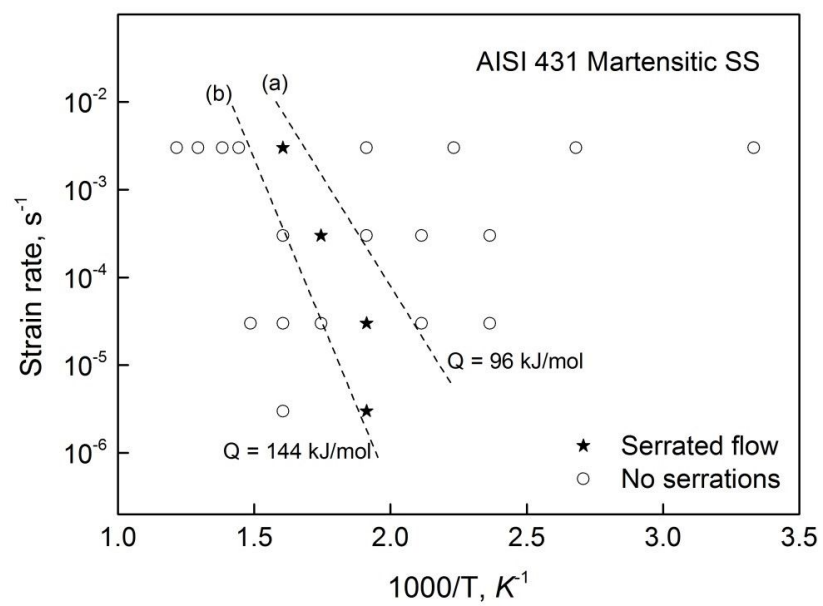

Figure 10: Arrhenius plot of Log[strain rate] vs (1000/Temperature) for the appearance of serrations/jerky flow in the tensile curve of AISI 431 martensitic stainless steel.

a smooth flow can be used to evaluate the average activation energy, $Q$ for serrated flow. The activation energy is estimated as

$$
Q=\text { slope } \times 1000 \times R \times 2.303,
$$

Where $R$ is the universal gas constant [22, 23]. In the $\log (\epsilon)$ $-1000 / T$ plot (Figure 10), the serrated flow was found to be well encompassed by two mean empirical lines (a) and (b) which well-represent the onset and disappearance of serrated flow respectively. The values of activation energy for the onset of serrated flow as $Q=96 \mathrm{~kJ} \mathrm{~mol}^{-1}$ and for the disappearance of serrated flow as $Q=144 \mathrm{~kJ} \mathrm{~mol}^{-1}$ have been obtained from the slopes of lines (a) and (b), respectively.

The activation energy of $96 \mathrm{~kJ} \mathrm{~mol}^{-1}$ observed for the onset of serrated flow process in the present investigation
(Figure 10) compares favourably with the reported values of $76-103 \mathrm{~kJ} \mathrm{~mol}^{-1}$ for the diffusion of interstitial solutes such as carbon in BCC iron and steels [24-26]. The obtained activation energy of $144 \mathrm{~kJ} \mathrm{~mol}^{-1}$ for the disappearance of serrated flow in the AISI 431 steel, is in agreement with the reported values in the range of $128-167 \mathrm{~kJ} \mathrm{~mol}^{-1}$ for the disappearance of serrations towards the end of serrated flow temperature regime in low carbon steels $[25,26]$. From their studies on 2.25Cr-1Mo steel, Hayes et al. [27] have also reported the activation energy for the disappearance of serrations to be between $130-155 \mathrm{~kJ} \mathrm{~mol}^{-1}$. In $2.25 \mathrm{Cr}$ 1Mo, P9 and P91 ferritic steels, based on the values of activation energy, locking of mobile dislocations by diffusing carbon atoms were identified to be the source of serrations [14, 18-20]. From the activation energy values obtained for the onset of serrations in the present study, it is suggested that the occurrence of dynamic strain ageing can be attributed to the diffusion of interstitial carbon in the AISI 431 steel. Whereas, the higher activation energy values obtained for the disappearance of serrations is attributed to the sum for the activation energy for the diffusion of interstitial solute and the binding energy of the solute to dislocation [25]. DSA causes an increased rate of dislocation multiplication and delay in recovery of dislocation structure, and promotes an increased propensity towards a uniform distribution of dislocations rather than cell structures in many metals and alloys [28, 29, 33]. The dislocation density in the DSA regime was also observed to be higher, compared to that observed at room temperature. Keh et al. [25] reported higher dislocation density in $0.35 \%$ C steel in the DSA regime. In low carbon martensitic steel, uniform dislocation distribution characterized by linear arrays of screw dislocations were observed in the strain rate range of serrated flow [33]. A significant increase in dislocation density in the DSA temperature regime than those at room and high temperatures was reported for P91 steel [34]. Morris [31] pointed out that the tendency to produce a non-cellular array of dislocations increases with an increase in the intensity of dynamic strain ageing. These investigations indicate reduced dynamic recovery in the DSA regime arising from the diffusion of solutes, which affects the rate of dynamic recovery by pinning of dislocations and thereby preventing screw dislocation to cross slip due to its reduced mobility.

\subsection{Tensile Flow Behaviour}

Figure 11 shows tensile flow behaviour of AISI 431 martensitic SS, as the variations in true stress with true plastic strain, within the uniform plastic deformation region, for 
Table 3: Goodness of fit in terms of $\chi^{2}$, for various constitutive relations to the tensile flow behaviour of AISI 431 martensitic stainless steel.

\begin{tabular}{cccccc}
\hline Temperature K & \multicolumn{3}{c}{ Goodness of fit, $\chi^{2}$} & Loce \\
\hline 300 & Hollomon & Ludwigson & Swift & 6.14 & 15.20 \\
473 & 111.61 & 0.98 & 8.98 & 7.32 & 7.34 \\
448 & 98.77 & 1.32 & 6.22 & 4.60 & 13.82 \\
523 & 70.28 & 0.90 & 6.53 & 3.18 & 1.97 \\
573 & 69.84 & 1.26 & 1.87 & 6.50 & 29.39 \\
623 & 19.69 & 2.42 & 3.08 & 11.58 & 58.65 \\
673 & 19.61 & 2.44 & 16.37 & 1.12 & 12.07 \\
723 & 4.72 & 0.28 & 1.50 & 1.74 & 5.92 \\
773 & 2.82 & 0.96 & 1.18 & 3.88 & 3.56 \\
823 & 1.45 & 3.99 & 3.25 & 5.23 & 2.71 \\
\hline
\end{tabular}

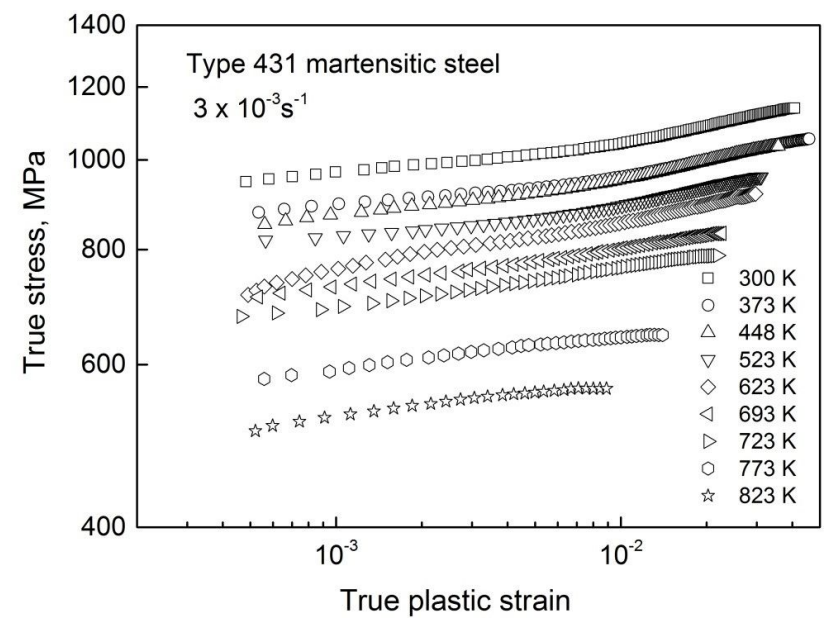

Figure 11: Variation of true stress as a function of true plastic strain for the AISI 431 steel in the temperature range of 300-823 K.

the temperature range of 300-823 K. The double logarithmic plot of $\sigma-\epsilon$ data exhibited a curvilinear behaviour with positive stress deviations at lower strains from the extrapolated linear $\sigma-\epsilon$ data at high strains for the room and intermediate temperatures. The extent of positive stress deviation at low strains decreases with increasing temperature. At the higher temperatures, $\sigma-\epsilon$ plots exhibited a linear for the entire uniform plastic deformation regime with marginal negative stress deviations at the higher stresses, indicating saturation in stress values at strains close to the onset of instability. The flow stress values corresponding to respective true strain values decrease systematically with increasing temperature. The decrement in flow stress values with increasing temperature in the intermediate temperature range of 373 to $623 \mathrm{~K}$ was observed to be insignificant, whereas at high temperatures in the range $673-823 \mathrm{~K}$ a rapid decrease in flow stress was observed. Besides the

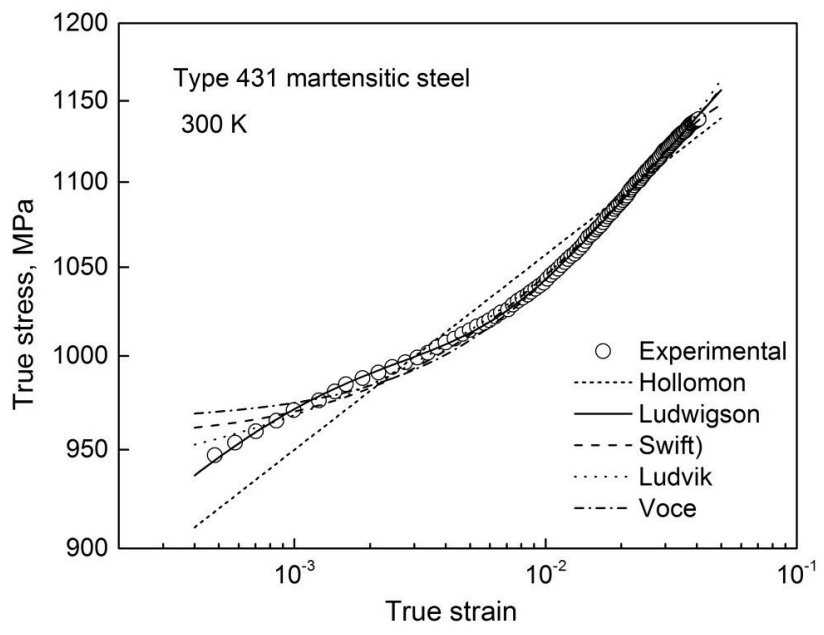

Figure 12: Applicability of various flow relationships namely, Hollomon, Ludwigson, Swift, Ludvik and Voce to describe the flow behaviour of AISI 431 steel at $300 \mathrm{~K}$.

flow stress values, the true uniform plastic strain values were observed to systematically decrease with increasing temperature from 300 to $823 \mathrm{~K}$.

Various flow relations proposed in the literature such as Hollomon [7], Ludvik [9], Swift [10], Ludwigson [11] and Voce [12] were employed to describe the tensile flow behaviour of AISI 431 martensitic stainless steel in the temperature range of 300-823 K. Applicability of various flow relationships in describing the observed $\sigma-\epsilon$ data is demonstrated at $300 \mathrm{~K}$ in Figure 12. Table 3 gives the $\chi^{2}$ value obtained for various flow relationships in describing the $\sigma-\epsilon$ curve of the AISI 431 steel at different temperatures. Ludwigson relation was found to best describe the flow behaviour in the temperature range of 300-773 K, with the lowest $\chi^{2}$ values which indicated the goodness of the fit. At the high temperatures of 773 and $823 \mathrm{~K}$, Hollomon 


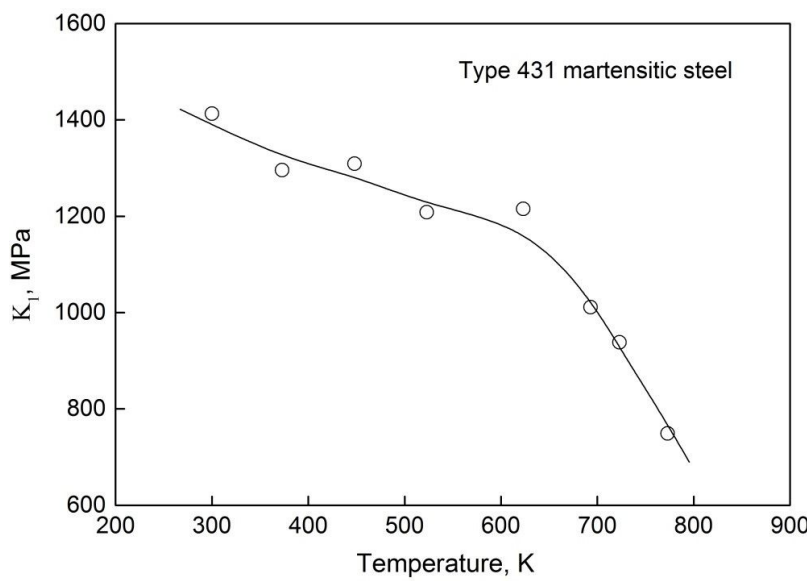

Figure 13: Variation of Ludwigson / Hollomon work hardening parameter $K_{1}$ with temperature for the AISI 431 steel.

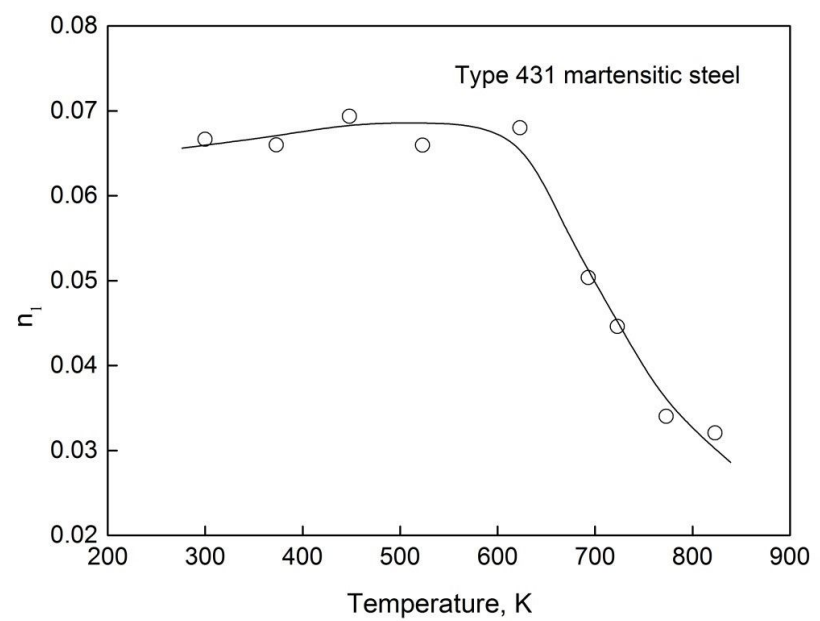

Figure 14: Variation of Ludwigson / Hollomon work hardening parameter $n_{1}$ with temperature for the AISI 431 steel.

equation was found to well-describe the flow relation with low $\chi^{2}$ values. It may be noted that Hollomon relation is obtained on the boundary condition that the second term in the Ludwigson relation becomes negligible.

Following Ludwigson [11], the transition strain, $\epsilon_{t r}$, below which positive deviation in flow stress at low strains from the Hollomon representation of the $\sigma-\epsilon$ data, was evaluated by setting the value of the ratio $r$ defined as

$$
r=\frac{\exp \left(K_{2}+n_{2} \epsilon\right)}{K_{1} \epsilon^{n_{1}}},
$$

to an arbitrary value of 0.001 . The transition stress $\sigma_{t r}$ corresponding to $\epsilon_{t r}$ was then evaluated from Hollomon equation. The applicability of Hollomon equation at high temperatures consistent with those reported for $9 \mathrm{Cr}-1 \mathrm{Mo}$ ferritic steel [19] and description of flow behaviour by Hollomon equation has been attributed to the predominance of cross-slip at high temperatures.

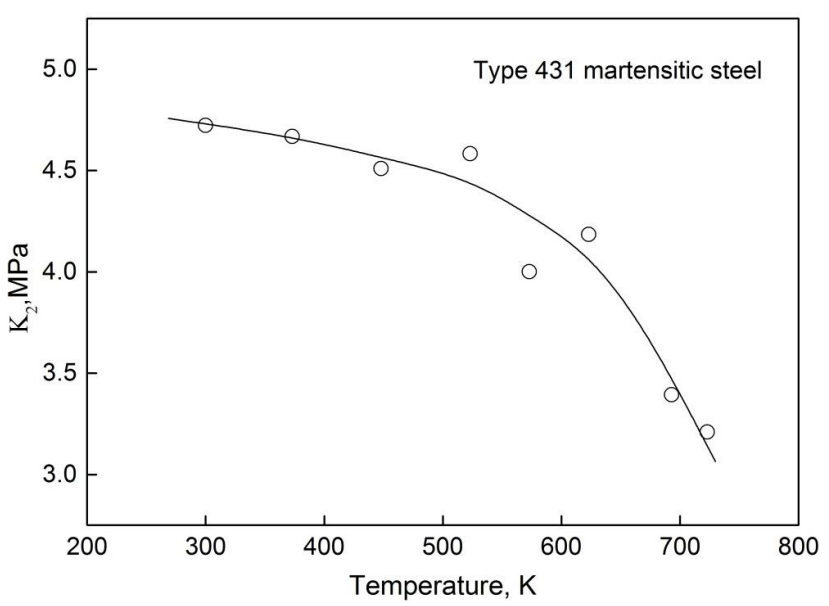

Figure 15: Variation of Ludwigson work hardening parameter $K_{2}$ with temperature for the AISI 431 steel.

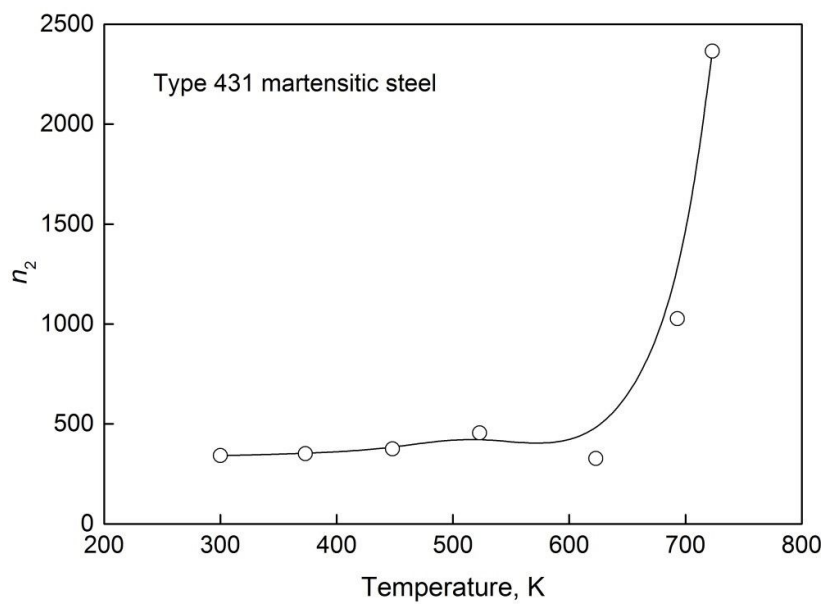

Figure 16: Variation of Ludwigson work hardening parameter $n_{2}$ with temperature for the AISI 431 steel.

\subsection{Variations of Work Hardening Parameters with Temperature}

Figures 13-16 show the variations of work hardening parameters $K_{1}, n_{1}, K_{2}$ and $n_{2}$ of the Ludwigson equation obtained for fitting stress-strain data with the temperature at the strain rate of $3 \times 10^{-3} \mathrm{~s}^{-1}$. Figures 17 and 18 show the variation of transition strain, $\epsilon_{t r}$, and transition stress, $\sigma_{t r}$, respectively, with temperature for the type 431 steel. The variation of $K_{1}$ and $K_{2}$ with temperature exhibited a gradual decrease to a plateau in values from room temperature to intermediate temperatures followed by a rapid decrease in the value at high temperatures (Figure 13 and 15). The variation of $n_{1}$ with temperature exhibited a gradual increase to a peak value at the intermediate temperature, followed by a rapid decrease at high temperatures (Figures 14). The additional constant in the Ludwig- 


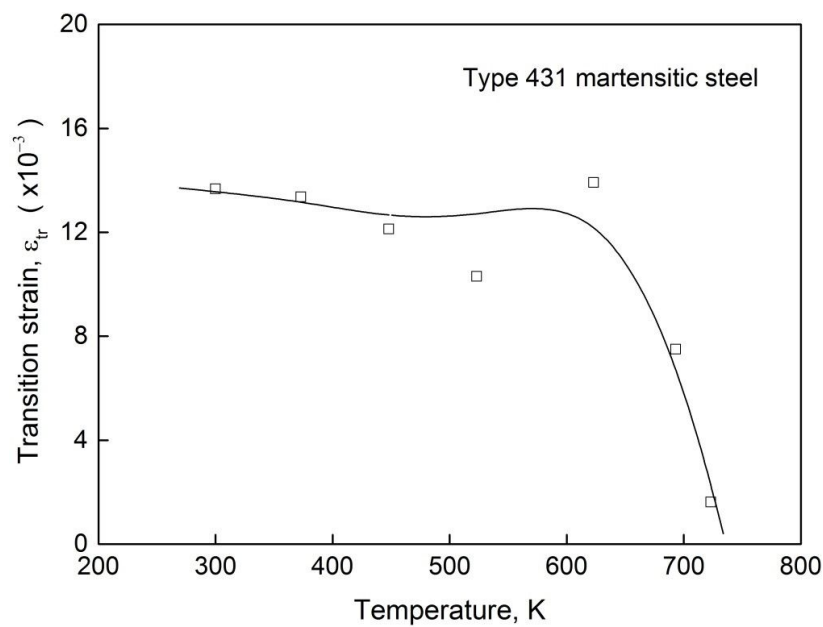

Figure 17: Variation of Ludwigson transition strain $\epsilon_{t r}$ with temperature for the AISI 431 steel.

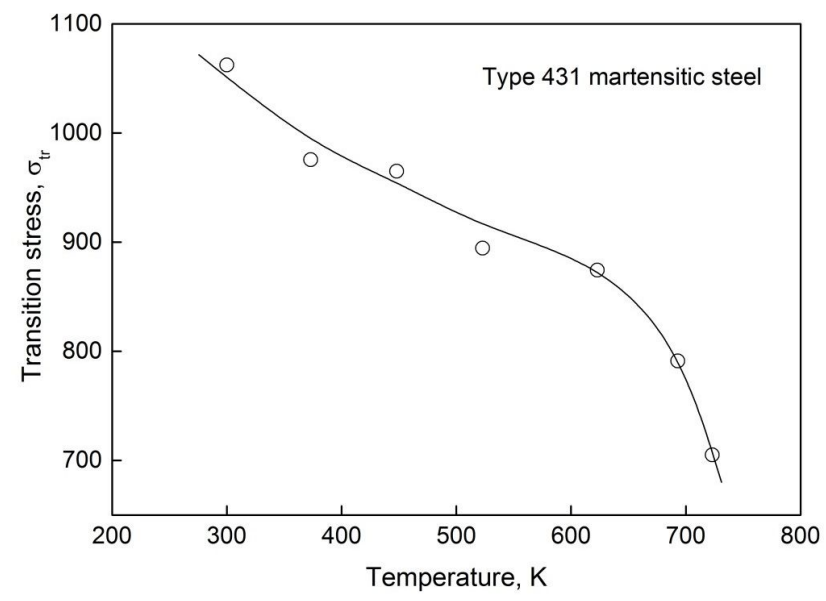

Figure 18: Variation of Ludwigson transition stress $\sigma_{t r}$ with temperature for the AISI 431 steel.

son equation $n_{2}$ exhibited a marginal increase (in the negative scale) in the temperature range 300 to $823 \mathrm{~K}$ and a rapid increase at high temperatures (Figure 15). Both $\epsilon_{t r}$ and $\sigma_{t r}$ exhibited a gradual decrease up to a plateau at intermediate temperatures followed by a rapid decrease at high temperatures (Figures 17 and 18). It is reported [35] in $316 \mathrm{~L}(\mathrm{~N})$ steel that the work hardening strain parameters $n_{1}$ and $\epsilon_{T}$ were found to scale with the uniform strain and the work hardening strength parameters $K_{1}, K_{2}$ and $\sigma_{t r}$ were found to scale with the tensile strength. The observed similarity in the variation of work hardening parameters (Figures 13-15, 17 and 18) and tensile properties (Figures 2-6) with temperature may be attributed to the scaling of work hardening parameters with respective uniform strain or tensile strength. The variation in $n_{2}$ was found to indicate the magnitude of deviation from the Hollomon relation at low strains and the high negative value of $n_{2}$ observed at high temperatures indicate the negligible second term of Ludwigson relation at these temperatures.

The observed variations in work hardening parameters with temperature are also consistent with those reported for ferritic and austenitic steels exhibiting dynamic strain ageing at intermediate temperatures [14, 18, 20, 21]. In the temperature range of 300-448 $\mathrm{K}$, marginal variation in flow stress/strength values and work hardening parameters results from the ease of deformation due to easy glide and cross-slip activity with an increase in temperature. At intermediate temperatures, the plateaus in strength values (Figures 2 and 3) and work hardening parameters (Figures 13-15, 17 and 18), negative strain rate sensitivity (Figure 9) and ductility minima (Figures 5 and 6) indicate the influence of DSA. It had also been reported that DSA causes increased hardening and delay in recovery of dislocation structure in many metals and alloys [25, 2832]. The rapid decrease in strength values and work hardening parameters, and increase in ductility with an increase in temperature observed at elevated temperatures (Figures 2-5, 13-15, 17 and 18) suggest the dominance of thermally accelerated dynamic recovery processes such as dislocation climb and cross-slip in the AISI 431 steel [36]. The rapidly increasing influence of dynamic recovery compares favorably with the reported observations in ferritic and austenitic steels [13, 14, 30, 32]. Significant decrease in strength values at high temperatures can result from increasing dislocation substructural softening resulting from dynamic recovery effects.

\section{Conclusions}

Detailed investigation on tensile deformation, fracture and work hardening behaviour of AISI 431 martensitic stainless steel exhibited distinct intermediate and high temperature regimes in the variations of tensile strength values, tensile ductility and work hardening parameters. The fracture mode remained transgranular for the range of temperatures examined. Anomalous variations in terms of peaks in flow stress/strength values, ductility minima and serrated/jerky flow at the intermediate temperatures indicate the manifestation of dynamic strain ageing occurring at these temperatures. Measurement of activation energy suggested that diffusion of interstitial carbon is responsible for DSA in the steel. At high temperatures, rapid decrease in flow stress/strength values and work hardening rate, and an increase in ductility with the increase in temperature indicated the dominance of dynamic recovery. 
Acknowledgement: The authors are thankful to GTRE and IGCAR for providing the facilities to carry out the present investigation and permission to publish it.

\section{References}

[1] Elevated-Temperature Properties of Stainless Steels. In: Properties and Selection: Irons, Steels, and High-Performance Alloys, ASM Handbook, ASM International, 1990, Vol. 1, 930-949.

[2] Standard Specification for Stainless Steel Bars and Shapes, ASTM standards, ASTM Inter, Pennsylvania, USA, 2013, A276-13a

[3] K.P. Balan, A.V. Reddy, D.S. Sarma, Scripta Mater, 39 (1998) 901 905.

[4] L. Ning, D. Zhonggang, H. Menggen, Mater Sci Technol, 7 (1991) 1057-1062.

[5] Rajasekhar, G. M. Reddy, T. Mohandas, V. S. R. Murti, Mater. Sci. and Technol., 24 (2008) 201-212.

[6] S. D. Washko, G. Aggen, ASM Handbook, Volume 1, ASM International, 1990, pp. 841-907.

[7] J. H. Hollomon, Trans AIME, 162 (1945) 268-90.

[8] U. F. Kocks, In: R. W. Rhode, J. C. Swearenger (Eds), Texture and Anisotropy: Preferred Orientations in Polycrystals and their Effort on Materials Properties ASTM STP 765, Philadelphia, American Society for Testing and Materials, 1982, pp. 121-138.

[9] P. Ludwik, Verlag Von Julius Springer, Leipzig, 1909, p 32.

[10] H. W. Swift, J. Mech. Phys. Solids, 1 (1952) 1-18.

[11] D. C. Ludwigson, Metall Trans, 2 (1971) 2825-2828.

[12] E. Voce, J. Inst. Met., 74 (1948) 537-562.

[13] B. K. Choudhary, K. B. S. Rao, S. L. Mannan, B. P. Kashyap, J. Nucl. Mater., 273 (1999) 315-325.

[14] E. Isaac Samuel, B. K. Choudhary, and K. B. S. Rao, Mater. Sci. Technol., 23 (2007) 992-999.

[15] P. Rodriguez, Bull. Mater. Sci., 6 (1984) 653-663.

[16] P. Rodriguez, In 'Encyclopedia of Materials Science and Engineering Supplementary Vol 1' ed Cahn RW Pergamon Press, Oxford, (1988) 504-508.
[17] R. L. Klueh, J. Nucl. Mater., 68 (1997) 294-307.

[18] B. K. Choudhary, K. B. S. Rao, S. L. Mannan, and B. P. Kashyap, Mater. Sci. and Tech., 15 (1999) 791-797.

[19] J. Christopher, B. K. Choudhary, E. Isaac Samuel, M. D. Mathew, and T. Jayakumar, J. of Nucl. Mater., 420 (2012) 583-590.

[20] K.S. Chandravathi, K. Laha, K. B. S. Rao, and S. L. Mannan, Mater. Sci. and Technology, 17 (2001) 559-565.

[21] K. G. Samuel, S. L. Mannan, and P. Rodriguez, Acta Metall., 36 (1988) 2323-2327.

[22] D. Blanc and J. L. Strudel, In: H. J. McQueen, J. P. Bailon, J.I. Dickson, J. J. Jonas, and M. G. Akben (Eds.), Strength of Metals and Alloys (ICSMA 7), Vol. 1, Pergamon Press, Oxford, (1986) pp. 349 354.

[23] S. Venkadesan, C. Phaniraj, P. V. Sivaprasad, and P. Rodriguez, Acta Metall., 40 (1992) 569-580.

[24] A. W. Sleeswyk, Acta Metall., 8 (1960) 130-132.

[25] A. S. Keh, Y. Nakada, and W. C. Leslie, "Dislocation Dynamics", A. R. Rosenfield et al. (Eds.), Mc Graw-Hill, New York, (1968), 381-408.

[26] J. D. Baird, Metall. Rev., 16 (1971) 1-18.

[27] R. W. Hayes and W. C. Hayes, Acta Metall., 32 (1984) 259-267

[28] J. W. Edington and R. E. Smallman, Acta Metall., 12 (1964) 13131328.

[29] D. J. Dingley and D. McLean, Acta Metall., 15 (1967) 885-901.

[30] D. J. Michel, J. Moteff, and A. J. Lovell, Acta Metall., 21 (1973) 1269-1277.

[31] J. G. Morris, Mater. Sci. Eng., 13 (1974) 101-108.

[32] B. P. Kashyap, K. McTaggart, and K. Tangri, Phil. Mag., 57 (1988) 97-114.

[33] S. Okamato, D. K. Matlock, and G. Krauss, Scripta Metall., 25 (1991) 39-44.

[34] A. K. Roy, P. Kumar, and D. Maitra, Mater. Sci. Eng. A, 499 (2009) 379-386.

[35] E. Isaac Samuel and B. K. Choudhary, Mater Sci and Eng A, 527 (2010) 7457-7460.

[36] B. K. Choudhary, K. B. S. Rao, and S. L. Mannan, Int. J. Pres. Ves. \& Piping., 58 (1994) 151-160. 